\title{
Community Perceptions on the Provision of Quality Health Care in Ghana: The Case of Kassena- Nankana Mutual Health Insurance Scheme
}

\author{
Kennedy A. Alatinga \\ Ph.D. Student in Public Policy and Administration, School of \\ Government, University of the Western Cape, South Africa \\ kalatinga@gmail.com \\ and \\ John J. Williams \\ Governance and Development Planning in the School of Government, \\ University of the Western Cape, South Africa \\ DOI: http://dx.doi.org/10.4314/gjds.v11i2.6
}

\begin{abstract}
This paper examines community perceptions on the provision of quality health care in the Kassena-Nankana District in Ghana. The paper examines the relationship between Ghana's National Health Insurance Scheme (NHIS) and the provision of quality health care, given that quality health care is an important determinant of access to health. Using a mixed methods research design, the researchers compared the perceptions of the insured and the uninsured people with respect to their perceived quality of health care received at health facilities. While the results of the household survey suggest that there is no statistically significant difference between the quality of health care received by either the insured or the uninsured, the focus group discussions indicate that the uninsured are attended to more quickly and are given more respect. The results highlight the perception that quality drugs are unavailable. The researchers recommend adequate supplies of good quality drugs to encourage utilisation of health services.
\end{abstract}

Key Words: Community, Perceptions, Quality health care, Ghana, Health Insurance

\section{Introduction and Background}

The National Health Insurance Scheme (NHIS) in Ghana was established by an Act of parliament (Act 650) in 2003, and, passed into law, legislative instrument, LI 1809 in 2004 (Government of Ghana, 2004). The NHIS is considered a more equitable and pro-poor 
health financing policy (Government of Ghana, 2003). The NHIS replaced the hitherto, out-of-pocket payment system where patients had to pay cash at the point of demanding health care. The prime aim of the NHIS is to attain universal health insurance coverage to persons resident in the country, ensure equity in health care coverage, access by the poor to health care services and the protection of the poor and vulnerable against financial risk (Government of Ghana, 2012:7). The NHIS gives prominence to community/district mutual health insurance schemes in all parts of the country as a vehicle for extending social protection in health to every Ghanaian. By giving prominence to community/ district mutual health insurance schemes, the NHIS seeks to promote community participation and local ownership in the management of the schemes, which will not only give voice to the local population but will also, enhance the sustainability of the schemes. Arhinful (2003) argues that community participation and local ownership, potentially give members a sense of responsibility that is necessary for curbing abuse or over use. The NHIS also permits the operation of private and commercial health insurance schemes and citizens may elect to enroll in such schemes (Government of Ghana, 2012).

The NHIS is publicly financed from a National Health Insurance Fund (NHIF). The NHIF draws its finances from three main sources: a 2.5\% Value Added Tax (VAT) known as the National Health Insurance Levy, a 2.5\% contribution from the Social Security and National Insurance Trust (SSNIT) for mainly public and private formal sector employees and annual premiums paid by mainly informal sector workers to the scheme (Aryeetey et al., 2013). The NHIS has a reasonably generous benefit package-covering $95 \%$ of disease conditions that afflict people in Ghana. Some of the benefits covered include: out-patient services, inpatient services, oral health and maternity care. The NHIS however, excludes the following services: appliance, prostheses, rehabilitation, dentures, organ and cosmetics surgery and assisted reproduction, HIV retroviral drugs, hormone and organ replacement therapy, heart and brain surgery other than accident, diagnosis and treatment abroad, dialysis for chronic renal failure and cancers (Government of Ghana, 2003).

Since its implementation ten years ago, several studies have explored different aspects of the NHIS and its potential to increase access to health care, including: the equity of premiums, its ability to improve the poor's access to health care, subscribers perceptions about service provision, its financial sustainability as well as financial protection against the costs of illness (Amporfu 2013; Derbile \& Geest 2013; Dixon et al. 2013; Barimah \& Mensah, 2013; Witter \& Garshong, 2009; Rajkotia, \& Wang, 2011). Even so, few of these studies have focused on the NHIS and the provision of quality health care, which is the focus of this paper. The rest of the paper is organised as follows. Section two presents the research problem while section three seeks to conceptualise the provision of quality health care services. In section four, the research setting, design and methods are discussed. The research results are then presented in sections five and six. Section five is devoted to the analysis of the quantitative results. The qualitative results are presented in section six. Section seven concludes the paper with discussions, conclusions and recommendations. 


\section{Problematising Quality Healthcare}

Despite the high scholarly interest in the NHIS since its implementation, to date very few studies have explored the relationship between the NHIS and the provision of quality health care (Turkson, 2009; Boateng \& Awunyor-Vito, 2013). The attention is often paid to financial and geographical barriers to health care. While financial and geographical barriers to health care are necessary, they may not be sufficient in explaining access to health care in general. For this reason, the authors argue that, in trying to understand the factors affecting access to health care, the important issue of quality health care needs to be addressed in an appropriate and timely manner by public health policy makers.

The motivation for this line of argument is that there is a vital connection between access to health care and quality of health care. For example, Asenso-Okyere, Anum, Osei-Akoto, and Adukonu (1998) suggest that where citizens perceive health care services to be of high quality, the demand for these quality services increases. On the other hand, citizens whose financial means already limit their access to health care may further exclude themselves even from affordable health services if they perceive those services to be of poor quality. Offei, Banner and Kyereme (2004: viii) contend that quality of health care depends upon attention paid to the needs of patients, including but not limited to accurate diagnosis and appropriate treatment and also prompt attention to patients. The authors argue "poor quality causes loss of lives, loss of revenue, low morale among health workers, and poor reputation of health care providers." Building on this perspective, Turkson (2009:65) asserts that if health programmes are to succeed in poor countries, it is imperative to solicit the views of local people regarding their degree of satisfaction with available services.

Donabedian (1980) points out that patient perception is significant because it impacts health-seeking behaviour, including the use of services, and it provides information to policy makers, that is relevant to improving the quality of health care services. In the same vein, Sharma and Narang (2011) suggest that the quality of health care is important and demands unrelenting attention from policy makers in order to improve health care delivery in general. Based on Sharma and Narang's (2011) research in rural India, they explained that financial and physical access are not the only important factors in determining optimal use of health care services; equally important are various aspects of quality, including manner of delivery and interpersonal and diagnostic aspects of care. This finding complements earlier studies in Cameroon that show that when user-fees are accompanied by quality improvements, the demand and use of health services increase even for people with low socio-economic status (Litvack \& Bodart, 1993). Further evidence for this trend was found in research on Burkina Faso pointing out that understanding populations' perceptions about quality health care is important for developing measures to increase the use of health care services (Baltussen, Yé, Haddad, \& Sauerborn, 2002). 
In Ghana, earlier research by Asenso-Okyere, Anum, Osei-Akoto, and Adukonu (1998) suggests that patients preferred to seek health care from mission clinics because of the perceived quality of health care they receive from the mission clinics despite relatively higher charges as compared to government health facilities. This evidence linking quality health care and the demand for, and use of health services highlights the need for an investigation of the current Ghanaian context. In this light, the researchers examine the NHIS and how it addresses the issue of quality health care delivery for its patients. Because the issue of quality health care is not adequately investigated with respect to peoples' insurance status, this research explores whether or not the peoples' insurance status influences the quality of care they receive. In order to achieve this objective, the study compares the quality of health care received by the insured and uninsured in an attempt to provide reliable information to policy-makers about the areas that need attention in order to improve quality of health care in Ghana.

\section{Conceptualising the Provision of Quality Health care Services}

Quality health care is a multi-dimensional concept, referring to different things for different stakeholders such as health providers, governments, and patients, based on subjective interpretations that are influenced by different socio-cultural settings.

According to Zineldin, "good quality of care is considered the right of all patients and the responsibility of all staff within the hospital"(Zineldin, 2006:61). Quality health care is generally understood as services that meet set standards for excellence, and that satisfy the needs of both consumers and health professionals in a way that adds significant meaning to both parties' health care experiences (Arries \& Newman, 2008). Given these perspectives, quality health care can be considered in three dimensions including the patients, health professionals (staff) and institutional/managerial (hospital) dimensions. Akin to these three dimensions is what Sharma and Narang (2011:52) identified as the three "stakeholder" components of quality: patients, professionals, and managers (Ovretveit, 1992 cited in Sharma \& Narang 2011:52). From the patient's perspective, quality means meeting the patient's unique needs and wants at the lowest cost, provided with courtesy and on time. To the professionals, quality involves the carrying out of techniques and procedures essential to meet the patient's requirement. And quality from the managers' point of view entails optimum and efficient utilisation of resources to achieve the objectives defined by higher authorities.

Arries and Newman (2008) argue that quality health care should be appreciated within the philosophy of "Batho Pele", a Sotho translation for "people first", suggesting consumers of health care be placed at the centre of health service delivery, and that health care delivery be transformed to satisfy the needs of patients. Inherent in this Batho Pele philosophy is making health services people-centred and people-driven. In this vein, Downey-Ennis and Harrington (2002) assert that the health system must become more people-centred with the interests of the public, patients, and clients being given greater prominence and 
influence in decision-making at all levels. Supporting this argument, Arries and Newman suggest that "healthcare institutions must create a people-centred and people-driven service that is characterised by equity, quality, timeliness and strong code of ethics" (Arries \& Newman, 2008:42). This then raises the question of what patients consider to be quality health care.

In their investigation of patient satisfaction, Sofaer and Firminger (2005) defined and measured quality health care on expectation theories. The authors conclude that satisfaction is based on the difference between what one expects from health providers and what one actually gets. In other words, satisfaction is determined by the difference between a patient's standard of expectations, ideals, or norms and his or her perception of the experience of care, with satisfaction arising either from a confirmation of positive expectations or a subversion of negative expectations.

Taken together, the core of quality health care appears to rest on how health care services are people/patient-centred and people-driven, including prioritising patients' perceptions about health care, their satisfaction, and their right to health care. This notion of people's rights and people-centred health care services reinforces earlier work on human-centred development put forward by Paulo Freire (1970) and Friedmann (1992). In his work the "Pedagogy of the Oppressed", Freire points out that the oppressed need to become conscious of their living conditions and rights as citizens and mobilise communities to unite to find a way to improve their living conditions. Freire seems to suggest that patients will only be able to improve their quality of life only when their perceptions of the quality of health care are taken into consideration - because in seeking health care, patients enter into a dialogue with the health care providers. This entry into a dialogue presumes the equality of both parties predicated on mutual trust, and there must be equal mutual respect, care, and commitment from both parties.

Justifying the human-centred development on moral grounds, Friedmann (1992) highlights three foundations for people-centred development: human rights, citizen rights, and human flourishing. His idea of human rights resonates with the Universal Declaration of Human Rights (1948), giving potency to its civil, political, economic, and social dimensions, including liberty and basic needs. Accordingly, any willful exclusion from these rights is a kind of violence on the person excluded. On the issue of citizen rights, Friedmann accentuates the importance of the citizen relative autonomy vis-àvis the state, presuming, therefore, a modern, democratic state, where the holders of authority are ultimately accountable to the people organised as a political community. Friemann's third moral foundation is human flourishing, an evocative and open-ended term, suggesting the possibility of human beings achieving their full potential in life, because the essence of life is not just to live but also to prosper. In this light, the patientcentred perspective in health care can be linked to a drive for greater accountability and transparency in health care governance because accountability has implications for examining patient perceptions of quality. Accountability raises the question of whom patients should hold responsible for the quality of health care they receive. Amongst 
other conclusions, this means patients can only flourish as Friedmann suggests when the quality of health care they receive truly meets their health need.

Three criteria have been proposed for assessing the quality of health care: structure, process, and outcome (Donabedian,1980). Structure refers to a patient's rating of the physical environment in which the service takes place, while process refers to the patient's rating of interpersonal interactions with and between service personnel. Examples of process indicators of the quality of health care include: responsiveness, friendliness, empathy, courtesy, competence, and availability. The third criterion, health outcome, relates to improvements in the patient's health. Closely related to the Donabedian process indicators of quality health care is the World Health Organization's (WHO) concept of quality health care which relates to the responsiveness of the health system to the expectations of patients. These expectations include, respecting patient's dignity, autonomy, and confidentiality of information. It also looks at whether patients receive prompt and immediate attention in cases of emergency and reasonable waiting time in non-emergency cases. The WHO further argues that a responsive health care system should treat all patients equally without discriminations. The WHO asserts that evidence often shows that the poor, who, in the context of developing countries are mostly rural people, are treated less respectfully and are offered poorer quality services than the nonpoor, who are mostly urban dwellers (WHO, 2000:33).

The issue of health systems' responsiveness to the needs of patient in a timely and respectful manner is a key determinant of the use of health care services. For instance, studies in Tanzania suggest that people often bypass free public health care services perceived to have poor quality, and instead choose to access geographically distant services perceived to be of good quality, or even incur costs to access private services (WHO, 2006). A study in Ghana also revealed that consumers of private health services are about 12 percent more likely to be satisfied with the quality of services they receive than consumers of public health care services (Nketiah-Amponsah \& Hiemenz, 2009). However, the poor cannot afford user-fees, let alone the cost of private health care.

Drawing on the Donabedian process indicators assessment of quality health care and the WHO's concept of responsiveness, the researchers evaluate quality health care from the demand side. That is, the evaluation is based on the consumer's or the patient's assessment or understanding of quality health care focusing on five dimensions: availability and quality of drugs, patient knowledge about the NHIS benefit package, the average time it takes for a patient to be attended to (waiting time), attitude of health providers (Nurses) towards patients, and the general satisfaction with services that patients receive, as shown in figure 1. 


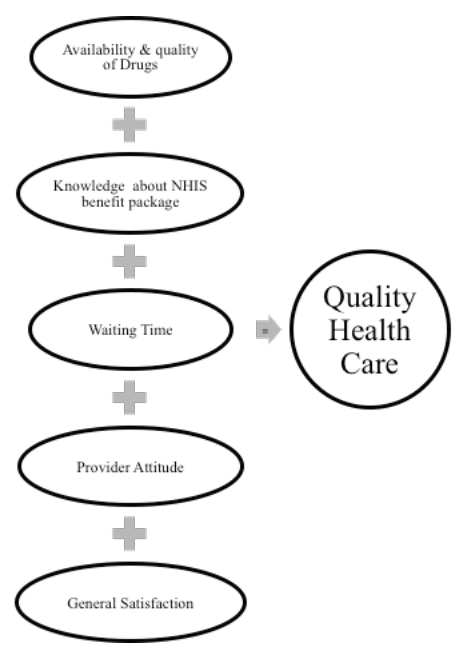

Figure 1: 5 Five dimensions of quality health care (Authors' Construct, 2013)

The availability and quality of drugs relates to patients' perceptions of the availability of medications they receive at the hospital and whether they perceive these medicines to be efficacious in the treatment of their ailments. The examination of patients' knowledge about the NHIS benefit package focused solely on the insured people because they are supposed to be educated about the NHIS benefit package-hence the objective was to find out whether or not insured people were aware that $95 \%$ of their medications are covered by the NHIS so as to enable them to demand their rights. The third dimension, waiting time, is self-explanatory, as it refers to the length of time it takes before health providers attend to waiting patients. Provider attitude describes the manner in which patients are treated, and general satisfaction refers to the overall rating patients give the services they receive at the facilities. These five criteria guide the interpretation of the empirical results.

\section{Methodology}

This research was conducted in the Kassena-Nanakana District (KND) in the Upper East Region of Northern Ghana between April and September 2009. KND is one of the nine districts in the Upper East Region and has Navrongo as its capital. The KND was randomly selected for the study. The Navrongo Demographic Surveillance System (NDSS) ${ }^{6}$ has a database of all households in the District hence it was very easy to locate respondents for the interviews. Two communities: Pindaa in the North and Gaani in the South were randomly selected for the research. Both communities are predominantly farming communities-84\% of the respondents in Gaani were farmers whereas $94 \%$

6 NDSS is a Unit of the Navrongo Health Research Centre that collects and updates demographic data in the Kassena-NankanaDistrict in Ghana. 
were farmers in Pindaa, depicting Pindaa as a rural community whereas Gaani is a periurban community. Literacy levels in both communities are very low: in Gaani, $84 \%$ of the respondents had never attended school while in Pindaa $88 \%$ had never attended school. Males constituted $74 \%$ of the respondents in Gaani and $88 \%$ in Pindaa, where females constituted $26 \%$ and $12 \%$.

In order to capture all five of the dimensions of quality health care, we adopted a mixed methods research (MMR) design. The rationale for adopting a MMR design is guided by the fundamental assumption that MMR provides a broader understanding of the research problem than either qualitative or quantitative approach alone (Teddlie \& Tashakkori, 2011). MMR offers a tool for understanding complex problems that are open to multiple constructions and interpretations such as quality health (Sharan, 2002). Both qualitative and quantitative methods have their own strengths and weaknesses, and using MMR the strengths can be combined to develop a more rigorous understanding of the research problem or questions. Specifically, we used the convergent parallel mixed methods design in which both quantitative and qualitative data are collected, analysed separately and the results are compared to see if the findings confirm or disconfirm each other (Creswell, 2014).

Cluster, stratified, simple random and purposive sampling techniques were used. With respect to cluster sampling, the study area has a dispersed settlement pattern hence the communities have been grouped into clusters by the Navrongo Demographic Surveillance System (NDSS). In this regard, cluster sampling was used to select the study communities. Considering the time -frame for the research and costs involved, random cluster sampling solved the problem of field assistants having to travel the length and breadth of these dispersed communities looking for respondents. Also, the population of each community was categorised into strata of the insured and non-insured, and stratified sampling was used select the samples. To do this, a sampling frame containing a list of all the insured in the selected communities was obtained from the office of the health insurance scheme, while a list of all the inhabitants of the two selected communities was obtained from NDSS. This list helped to establish the sampling frame of the non-insured from which the sample was drawn. In using stratified random sampling, both groups (insured and non-insured) were proportionately represented in the sample. Having stratified the population into the insured and uninsured, simple random sampling was then used to select 50 insured and 50 uninsured household heads for the interviews, bringing the total household interviews to 100 . Of the 50 insured respondents, $86 \%$ were men while $14 \%$ were women. The uninsured respondents were made up of $76 \%$ men and $24 \%$ women respectively. Purposive sampling was used to select respondents for focus group discussions (FGDs). Some of the respondents selected for the FGDs included opinion leaders such as assemblymen and some community members. A total of eight FGDs were carried out.

The selection of the sample size was guided by the principles that "decisions about sample size represent a compromise between the constraints of time and cost and the need for 
precision" (Bryman, 2008:179). The convergent parallel mixed methods approach was used to analyse data. This approach sought to explain similarities and differences between the two groups of respondents. Qualitative data were transcribed and categorised in line with the research question in order to discover essential patterns. The data were then analysed qualitatively in the form of narratives. Quantitative data on the other hand, were analysed using Microsoft SPSS 16.0.

\section{Quantitative Results}

The quantitative analysis focused on three of the five dimensions of quality health care waiting time, provider attitude, and the general satisfaction of patients about the services they received at the health facility. The data presented here are based on the respondents' perceptions on quality health care they receive at the War Memorial Hospital in Navrongo.

\section{Waiting time}

The waiting time refers to the length of time it takes before a patient sees a health provider at the health facility. Table 1 presents information about waiting time at the health facility for both groups. The household survey shows that nearly $60 \%$ of the uninsured receive medical attention immediately at the health facilities, whereas 50\% of the insured receive attention immediately.

Table 1: Waiting time at the war memorial hospital to see a health provider

\begin{tabular}{llll}
\hline $\begin{array}{l}\text { Waiting Time to see a health } \\
\text { provider }\end{array}$ & $\begin{array}{l}\text { Insured households } \\
\text { (Number/\%) }\end{array}$ & $\begin{array}{l}\text { Uninsured households } \\
\text { (Number/\%) }\end{array}$ & $\begin{array}{l}\text { Total } \\
\text { (Number/\%) }\end{array}$ \\
\hline Immediately & $25(50.00)$ & $28(58.33)$ & $53(54.08)$ \\
\hline Less than 30 minutes & $21(42.00)$ & $13(27.08)$ & $34(34.70)$ \\
\hline Between 30 minutes and 1 hour & $3(6.00)$ & $6(12.50)$ & $9(9.18)$ \\
\hline More than 1 hour & $1(2.00)$ & $2(4.08)$ & $3(3.03)$ \\
\hline Total & $\mathbf{5 0 ( 1 0 0 )}$ & $\mathbf{4 9 ( 1 0 0 )}$ & $\mathbf{9 9 ( 1 0 0 )}$ \\
\hline
\end{tabular}

Authors' Field Survey (2009)

The results from Table 1 suggest that about $8 \%$ of the uninsured are attended to more quickly than the insured. These results show apparent discrimination against the insured. This discriminatory practice contradicts the WHO demand that a responsive health system is required to treat all categories of patients equally without discrimination (WHO, 200o). Generally, the results from Table 1 show that all of the patients are attended to immediately or after waiting between 30 minutes and 1 hour, which may be considered quite reasonable. In this regard, the findings are consistent with Turkson's (2009:67) 
study, which concluded that majority of patients (83\%) found the waiting time at health facilities in Komenda-Edina-Eguafo-Abrem (KEEA) District in the Central Region of Ghana to be reasonable.

\section{Attitude of Health Providers (Nurses)}

Household heads were asked to rank their perception of health providers' attitudes (Nurses) towards patients using the following categories: very good, good, bad and very bad as shown in Table 2.

Table 2: Attitude of health providers (Nurses) at the war memorial hospital

\begin{tabular}{|c|c|c|c|}
\hline $\begin{array}{l}\text { Attitude of Health } \\
\text { Providers }\end{array}$ & $\begin{array}{l}\text { Insured households } \\
\text { (Number/\%) }\end{array}$ & $\begin{array}{l}\text { Uninsured households } \\
\text { (Number/\%) }\end{array}$ & $\begin{array}{l}\text { Total } \\
\text { (Number/\%) }\end{array}$ \\
\hline Very Good & $39(78.00)$ & $29(59.18)$ & 68 (68.69) \\
\hline Good & $11(22.00)$ & $20(40.82)$ & $31(31.31)$ \\
\hline Bad & $0(0.00)$ & o(o.oo) & $0(0.00)$ \\
\hline Very Bad & $\mathrm{o}(0.00)$ & $0(0.00)$ & $0(0.00)$ \\
\hline Total & $50(100)$ & 49 (100) & 99 (100) \\
\hline
\end{tabular}

\section{Authors' Field Survey (2009)}

These results in table 2 show that the attitude of nurses is not a critical issue as regards the delivery of quality health care as almost $70 \%$ of all respondents found the attitude of the health nurses to be very good. The results show that $78 \%$ of insured households ranked the attitude of health providers as very good, while 59\% of uninsured households ranked health providers' attitude as very good. These results contradict earlier studies that suggest patients, especially poor patients perceive the attitude of health providers to be very bad (Waddington \& Enyimayew, 1989a,199ob;WHO, 2000; Baltussen et al., 2002). Contradictory findings were also reported in a study in Egypt and Jordan, which indicated that patients are not satisfied with the responsiveness of nurses to their needs as well as with politeness. Thirty-eight percent of patients ranked the responsiveness of nurses as bad and $42 \%$ ranked their politeness as bad or very bad (Zineldin, 2006).

\section{Respondents' Satisfaction with Services at the War Memorial Hospital}

This dimension sought to evaluate the overall satisfaction of respondents about services received at the health facilities as shown in Table 3. 
Table 3: Respondents' satisfaction with services they receive at the war memorial hospital

\begin{tabular}{llll}
\hline $\begin{array}{l}\text { General Satisfaction with } \\
\text { Services }\end{array}$ & $\begin{array}{l}\text { Insured households } \\
(\text { Number/\%) }\end{array}$ & $\begin{array}{l}\text { Uninsured households } \\
\text { (Number/\%) }\end{array}$ & $\begin{array}{l}\text { Total } \\
\text { (Number/\%) }\end{array}$ \\
\hline Very Satisfied & $44(88.00)$ & $42(87.87)$ & $86(86.87)$ \\
\hline Somewhat Satisfied & $6(12.00)$ & $7(14.29)$ & $13(13.13)$ \\
\hline Not Satisfied & o(0.00) & o(0.00) & 0 (0.00) \\
\hline Total & $50(100)$ & $49(100)$ & $99(100)$ \\
\hline
\end{tabular}

\section{Authors' Field Survey (2009)}

As shown table 3, majority- $87 \%$ of both the insured and uninsured respondents indicated that they were very satisfied with the services. The results from Tables 1, 2 and 3 generally paint a good picture of the perceived quality of health care received at the health facilities for both the insured and uninsured respondents. In the light of these descriptive results, the Mann-Whitney U-test/Wilcoxon rank test was used to test the hypothesis: Ho: there is no difference in the quality of health care received by the insured and uninsured. The results show a Sig. (2-tailed) P-value of (0.365). This value is greater than 0.025 (0.365>0.025). The alternative hypothesis $\mathrm{H}_{1}$ : the insured received better quality health care than the uninsured. Therefore, the alternative hypothesis that assumed that the insured receive better quality health care than the uninsured is rejected in favour of the null hypothesis. These results show that in the study population, there is no statistically significant difference between the quality of health care received by the insured or the uninsured. Based on these findings, it may be concluded that there is no difference in the quality of health care received by either the insured or uninsured.

These findings are good news for assessing whether or not the objectives of the NHIS are being achieved. Importantly, if the population appears to be satisfied with the health services they receive, then it is reasonable to conclude that these good health services will automatically attract more people to use these facilities. 


\section{Qualitative Results}

\section{Knowledge about the Benefit Package of NHIS}

Respondents were asked about their awareness of which drugs and services are covered by the NHIS. The majority (80\%) indicated that they had no knowledge about the benefit package of the NHIS. Given their inadequate knowledge about the NHIS benefits package, it is possible that insured clients might not be able to challenge health providers about the prescriptions they are given. The inadequate knowledge of the respondents about the NHIS benefit package coupled with the high illiteracy rate among the population may make it difficult for patients to demand their rights at health facilities. This situation may negatively affect patients' overall access to health care because perceived quality of health care is positively associated with patients' overall use of health facilities.

\section{Availability and Quality of Drugs}

The availability and quality of drugs is a very important determinant of health service utilisation. Mariko (2003) asserts that drug availability at public health facilities has a strong positive effect on the use of public these health facilities. To this end, the results of the FGDs suggest that respondents are generally not satisfied with the availability and quality of drugs they receive at health facilities. For example, some of the insured respondents claim that because they are insured, they are often given low quality drugs that cannot cure even a headache or that they are given prescriptions to buy quality drugs from the pharmacy out of their own pockets because such drugs are not covered by the NHIS. The essential reason for patients to visit a health facility is to get cured of whatever sickness they suffer from, so if the perceived availability and quality of drugs is poor, the tendency is that people will not use the health facilities. These results confirm earlier results from neigbouring Burkina Faso, where respondents criticised the unavailability of drugs as a major factor reducing use of health services (Baltussen et al., 2002). These findings call for health policy makers to make concerted efforts to improve the availability and accessibility of quality drugs at health facilities, especially in rural areas.

On the issues of waiting time and general responsiveness of health providers towards patients, FGDs with the insured seem to suggest that the uninsured are attended to more promptly and are better respected. The following narrative lends credence to this assertion;

"The NHIS is very good but one thing that we (insured) encounter is that when you have the insurance card and you go to the hospital, you do not receive quick services. The health providers rather treat the uninsured before they attend to us, the insured. The health providers get 'something' from the uninsured. With the insured, they know they cannot get anything from you so they will not have that time for you. When you go to the hospital and you don't control your anger, you will surely come home with your sickness untreated. 
They will shout at you in a way that your own father has never done. They

don't regard us the insured at all" (Field Interview, 2009).

Besides this complaint, the FGDs also suggest that some nurses are corrupt because they inflate the prices of certain drugs for the uninsured for their own advantage and hence tend to give the uninsured prompt attention. The problem of corruption has policy implications and warrants further investigation for two reasons. Firstly, corruption may drive people away from using health facilities. Secondly, patients who become victims of corruption may be pushed into serious depths of poverty, thus worsening the poverty situation of the people.

\section{Discussion of Findings}

The analysis of the results from the household surveys and FGDs show contrasting results. The results of the household survey do not show any differences in the quality of health care received by the insured and uninsured based on the hypothesis testing using the Mann-Whitney/Wilcoxon rank sum test (P-Value=0.365). The household survey results indicate that nearly 90\% of both insured and uninsured types of patients are immediately attended to or are attended to within 30 minutes. Well over half see the attitude of health providers to be very good and nearly 90\% are generally very satisfied with the services they receive from the health facilities. On the other hand, the FGDs show clear differences in the quality of health care received by the insured and uninsured. The FGDs suggest that the uninsured are attended to more promptly at the health facility and are better respected because they are paying cash. Anecdotal evidence also suggests that some nurses inflate the prices of certain drugs for the uninsured and hence tend to attend to them more promptly. Discrepancies in the availability and quality of drugs were highlighted in the FGDs. The uninsured are purportedly to be given quality drugs, whereas the insured who do not know what is covered by the NHIS are often asked to buy drugs from drugstores out of their own pockets, because such drugs are not covered by the NHIS. Adequate knowledge about the NHIS benefit package by the insured is essential in order to empower them (insured) to hold health providers accountable when their rights are violated. Empowering the insured with information about the NHIS benefit package may give meaning to Friedmann's (1992) idea of citizen rights as he underscores the importance of citizens' relative autonomy vis-à-vis the democratic state, where the holders of authority are ultimately accountable to the people organised as a political community.

However, these results are interesting for two reasons. Firstly, it appears qualitative methods might be more appropriate than quantitative methods for assessing the quality of health care since the qualitative methods allow the respondents to express their views freely thereby eliciting responses that quantitative methods may not. Secondly, the cultural setting of the respondents also seems to play a role. For instance, in the study area, when a person is very sick and is asked: "How is your health" the sick person always says "I am fine". The sick person never replies: "I am not fine". Thus it is likely that because 
the questionnaire asked directly about the attitude of health providers and satisfaction about the health services provided, both the insured and uninsured decided to say they were satisfied reflecting a peculiar cultural characteristic of the study area.

\section{Conclusion}

This paper has investigated the research question: What are community perceptions on the provision of quality health care in the Kassena-Nankana District in Ghana? More specifically, it investigated the relationship between Ghana's National Health Insurance Scheme (NHIS) and the provision of quality health care. The research compared the perceptions of the insured and the uninsured people with respect to their perceived quality of health care received at health facilities. Quality health care was evaluated from the demand side-based on the consumer's or the patient's assessment or understanding of quality health care, by focusing on five dimensions: availability and quality of drugs, patient knowledge about the NHIS benefit package, the average time it takes for a patient to be attended to (waiting time), attitude of health providers (Nurses) towards patients, and the general satisfaction with services that patients receive.

Whilst the results of the household survey suggested that there was no statistically significant difference between the quality of health care received by either the insured or the uninsured, the focus group discussions, however, indicated that uninsured users of the health services were attended to more quickly, and enjoyed a greater degree of respect at the War Memorial Hospital. The results of the FGDs point to an apparent discrimination against the insured users of the health facilities. Equally, important, our research results have confirmed the perception, amongst the health facility users, that quality drugs are unavailable.

A number of policy implications emerge from the research findings. The perceived poor quality of health care received by the insured may adversely affect future enrolment in the NHIS. Because if people are not satisfied with the quality of health care they receive under the NHIS, they may drop out from the scheme when their membership expires and may even discourage other people from joining the scheme. Patients'/citizens' inadequate knowledge about the NHIS benefits package is likely to make it difficult for insured clients to question health providers about medical prescriptions they are given.

\section{Recommendations}

It is recommended that the National Health Insurance Authority (NHIA) and the Ministry of Health carry out further research to find out why nurses purportedly attend to the uninsured more promptly because they pay cash. Addressing this question could provide valuable information to policy makers that are relevant to improving the quality of health care services. 
The allegation that some nurses illegally accept monetary bribes from the uninsured in order to provide them with more prompt service is a matter of serious concern and requires investigation by health authorities. For example, the health authorities need to investigate the nurses' motivation for taking bribes from uninsured patients at the War Memorial hospital.

There is the need for the management of the NHIS to organise massive educational campaigns to educate health seekers about the benefits to which they are entitled at health facilities. This education could empower citizens to demand their rights and also hold health providers accountable when their entitlements are not met.

Given the important role the availability and quality of drugs play in the overall use of health services, it is important for the National Health Insurance Authority (NHIA) and Ministry of Health to ensure that drugs are available for all consumers of health care services. Improving the availability and supply of quality of drugs would attract people to health facilities.

\section{References}

Amporfu, E. (2013). Equity of the premium of the Ghanaian national health insurance scheme and the implications for achieving universal coverage. International Journal for Equity in Health, 12(1), p.4.

Aryeetey, G. C., Jehu-Appiah, C., Kotoh, A. M., Spaan, E., Arhinful, D. K., Baltussen, R. and Agyepong, I. A. (2013). Community concepts of poverty: an application to premium exemptions in Ghana's National Health Insurance Scheme. Globalization and Health, 9(1), 12.

Arries, E. J. and Newman, 0. (2008). Outpatients' experiences of quality service delivery at a teaching hospital in Gauteng. Health SA Gesondheid, 13(1).

Asenso-Okyere, W. K. Anum, A., Osei-Akoto, I., and Adukonu, A. (1998). Cost recovery in Ghana: Are there any changes in health care seeking behaviour? Health Policy and Planning, 13(2), pp. 181-188.

Baltussen, R., Yé, Y. Haddad, S. and Sauerborn, R. S. (2002). Perceived quality of care of primary health care services in Burkina Faso. Health Policy and Planning, 17(1), 42-48. Barimah, K. B., \& Mensah, J. (2013). Ghana's National Health Insurance Scheme: insights from members, administrators and health care providers. Journal of Health Care for the Poor and Underserved, 24(3), pp.1378-1390.

Boateng, D. and Awunyor-Vito, D. (2013). Health insurance in Ghana: evaluation of policy holders' perceptions and factors influencing policy renewal in the Volta region. International Journal for Equity in Health, 12(50). 
Bryman, A. (2008). Social research methods (3rd ed.). Great Clarendon Street Oxford: Oxford University Press.

Creswell, J. W. (2014). Research design: qualitative, quantitative, and mixed methods approaches (4th Ed.). Thousand Oaks, CA: SAGE Publications.

Derbile, E. K. and Geest, S. van der. (2013). Repackaging exemptions under National Health Insurance in Ghana: how can access to care for the poor be improved? Health Policy and Planning, 28(6), pp.586-595.

Dixon, J., Tenkorang, E. Y. and Luginaah, I. (2013). Ghana's National Health Insurance Scheme: a national level investigation of members' perceptions of service provision. BMC International Health and Human Rights, 13(35).

Donabedian, A. (1980). The definition of quality and approaches to its assessment. Explorations in quality assessment and monitoring (Vol. 1). Ann Arbor, MI: Health Administration Press.

Freire, P. (1970). Pedagogy of the Oppressed. 8o Strand, London WC2r oRL, England: Penguin Ltd.

Friedmann, J. (1992). Empowerment: the politics of alternative development. Cambridge: Blackwell Publishers.

Government of Ghana. National Health Insurance (NHI) Act, (Act 650). , Pub. L. No. 650 (2003).

Government of Ghana. National Health Insuranc Regulation. Pub. L. No. (LI 1809) (2004).

Government of Ghana. National Health Insurance (NHI) Act, (Act 852 ). , Pub. L. No. 852 (2012).

Konadu-Agyemang, K. (2000). The Worst of times and the best of times: structural adjustments programs and uneven development in Africa: the case of Ghana. Professional Geographer, 53(3), pp. 469-483.

Litvack, J. I., and Bodart, C. (1993). User fees plus quality equals improved access to health care: Results of a field experiment in Cameroon. Social Science \& Medicine, 37(3), 369-383. Mamdani, M., \& Bangser, M. (2004). Poor people's experiences of health services in Tanzania: A Literature Review. Reproductive Health Matters, 12(24), pp. 138-153.

Mariko, M. (2003). Quality of care and the demand for health services in Bamako, Mali: the specific roles of structural, process, and outcome components. Social Science \& Medicine, 56(6), pp. 1183-1196. 
Nguyen, H. T. Rajkotia, Y. and Wang, H. (2011). The financial protection effect of Ghana National Health Insurance Scheme: evidence from a study in two rural districts. International Journal for Equity in Health, 10 (4).

Nketiah-Amponsah, E., and Hiemenz, U. (2009). Determinants of consumer satisfaction of health care in Ghana: does choice of health care provider matter? Global Journal of Health, 1(2), pp. 50-61.

Offei, A. K. Bannerman, C. and Kyeremeh, K. (2004). Healthcare quality assurance manual for sub-districts. Ghana Health Service. Retrieved from http://ghanaqhp. org/fileadmin/user_upload/QHP/Healthcare_Quality_subdistrict.pdf. Accessed: $9^{\text {th }}$ August 2013.

Sharan, B. (2002). Qualitative research in practice: Examples for discussion and analysis. San Francisco, CA: Jossey-Bass.

Sharma, J. and Narang, R. (2011). Quality of healthcare services in rural India: the user perspective. Vikalpa, 36 (1), pp. 51-6o.

Sofaer, S., and Firminger, K. (2005). Patient Perceptions of the Quality of Health Services. Annual Review of Public Health, 26(1), pp. 513-559.

Teddlie, C., and Tashakkori, A. (2011). Mixed methods research: contemporary issues in an emerging field, in Denzin, N.K., \&Lincoln, Y.S. (eds.), The SAGE handbook of qualitative research ( $4^{\text {th }}$ ed.). Thousand Oaks, CA: SAGE Publications, pp. 285-299.

Turkson, P. K. (2009). Perceived quality of healthcare delivery in a rural District of Ghana. Ghana Medical Journal, 43(2).

Waddington, C. J., and Enyimayew, K. A. (1989a). A price to pay: The impact of user charges in ashanti-akim district, Ghana. The International Journal of Health Planning and Management, 4(1), pp. 17-47.

Waddington, C., and Enyimayew, K. A. (1990b). A price to pay, part 2: the impact of user charges in the Volta region of Ghana. The International Journal of Health Planning and Management, 5(4), pp. 287-312.

World Health Organization (2000). The World health report 2000: health systems: improving performance. 1211 Geneva 27, Switzerland: World Health Organization.

World Health Organization (2006). Quality of care: a process for making strategic choices in health systems. 1211 Geneva 27, Switzerland: World Health Organization.

Zineldin, M. (2006). The quality of health care and patient satisfaction: An exploratory investigation of the $5 \mathrm{Q}$ s model at some Egyptian and Jordanian medical clinics. International Journal of Health Care Quality Assurance, 19(1), pp. 60-92. 